\title{
Moraic Coda Sonority in Chilean Spanish
}

\author{
Nate Shaftoe \\ York University
}

This paper discusses coda lenition phenomena in Chilean Spanish, seeking to create a unified analysis for coda obstruent gliding and /s/-reduction. The paper invokes Moraic Theory to motivate lenition of certain segments in coda position. Using Harmonic Serialism, a serial variant of Optimality Theory, Chilean Spanish is shown to have a minimum sonority requirement on coda segments, and lenites insufficiently sonorous segments. /s/ is shown to placedelete to [h] to avoid sonority restrictions. The lack of / $/$ / causes obstruents to diverge their derivation from that of $/ \mathrm{s} /$. Lenition to glottal segments is preferred, but gliding occurs if this is impossible.

\section{Introduction}

Coda lenition is a common phenomenon cross-linguistically, manifesting in such varied forms as final devoicing and even sometimes vocalization. Chilean Spanish undergoes segment lenition in the coda for both its obstruent stops and the fricative /s/ (Martínez-Gil 1997; Piñeros 200; Broś 2018)). However, /s/ and the stops lenite to different segments. When in coda position, Chilean Spanish /s/ lenites to [h] if wordinternal, and fully deletes if word-final (Broś 2018: 41). In contrast, Chilean Spanish stops /p, b, t, d, k, g/ lenite into glides if in coda position, regardless of whether the segment is word-final or not (Martínez-Gil 1997: 170; Piñeros 2001: 164-165;). Meanwhile, Chilean Spanish sonorants /n 1 r/ do not experience any lenition in coda position. Thus, any explanation of coda stop and /s/ lenition must also account for why sonorants are not also forced to lenite.

At a glance, the stop and /s/ patterns seem to have little in common. After all, glides and $/ \mathrm{h} / \mathrm{share}$ little in the way of features beyond [continuant]. However, this paper argues that these two phenomena are in fact derived from the same underlying principle: a disfavouring of moraic obstruents. As per Zec (1995) and Hayes (1989), this analysis assumes that syllable weight is determined by the presence of morae. Furthermore, this paper follows on from Zec's (1995: 85, 89-90) argument that languages can have minimum sonority requirements in regards to which segments can bear morae. Thus, this paper argues that Chilean Spanish has a high-ranked *OBSTRUENTMORA constraint which bans stops and fricatives from bearing morae. This triggers lenition in various forms. This paper argues that the preference is for placedeletion as per McCarthy (2008). However, a phonological gap in Chilean Spanish, the absence of / $/$, prevents licit place-deletion in stops (Lipski 1994; Martínez-Celdrán et al. 2003). This causes stop lenition to diverge from /s/ lenition, leading stops to glide and /s/ to reduce to [h] or fully delete.

This paper makes use of Harmonic Serialism (HS), a variation of Optimality Theory (OT; McCarthy 2016). While largely adhering to the underlying practice of OT, HS differs in adopting serial derivation. Candidates are limited to making only a single change to the input, such as voicing a consonant, at each step. EVAL then selects the most harmonic candidate at that step, and feeds it back into the derivation as the new input. This process continues until a winner is selected which is identical to the input at that step.

A comprehensive analysis of Chilean Spanish coda obstruent lenition has thus been constructed. Stops are driven to glide due to sonority and prosodic concerns: they must become something more sonorous than 
a stop, but must not add unnecessary prosodic structure. This paper argues that all leniting coda stops must gain [+continuant], and then [+sonorant]. Meanwhile, the features [rhotic], [lateral], and [nasal] would need to be added separately. Therefore, stops will become [+continuant, +sonorant] segments, that is, glides, due to having attained sufficient sonority to licitly bear morae.

In contrast, coda /s/ simply place-deletes, because Chilean Spanish permits [h]. This allows underlying /s/ to vacuously satisfy the sonority constraints on mora-bearing segments. This paper further proposes that when word-final, an otherwise unrelated constraint *FINAL/h causes full deletion.

Therefore, this paper argues that a single underlying process, the banning of obstruents from bearing morae, can account for the lenition of both stops to glides, and /s/ to [h] or [ø].

The paper is organized as follows: Section 2 introduces the data for this analysis. Section 3 discusses the assumptions on Gradualness this paper adopts. Section 4 defines the necessary constraints for this analysis. Section 5 provides the HS analysis for Obstruents, Sonorants, and the fricative /s/. Section 6 discusses the prediction of this analysis. Section 7 concludes.

\section{Data}

This paper considers data drawn from Chilean Spanish. The data shows two patterns of coda lenition, one for stops and another for the fricative /s/. The stop pattern is seen in (1), below.

(1) Stop Gliding (Piñeros 2001)
a. /adkirir/ [aj.kirir] 'to acquire'
b. /etniko/ [ej.niko] 'ethnic'
c. /kaptura/ [kaw.tura] 'capture'
d. /dogma/ [dow.ma] 'dogma'

As this data shows, Chilean Spanish lenites both voiced and voiceless stops to glides when they appear in the coda. The exact glide to which the stop lenites is dependent on the underlying stop: $/ \mathrm{p}, \mathrm{b} / \mathrm{lenite}$ to [w], /t, d/ lenite to [j], and /k, g/ can lenite to either, though generally to [w] (Piñeros 2001). For the purposes of this analysis, it is assumed that high-ranking IDENT constraints are enforcing these selections. For example, /t/ retains its [+coronal] feature, and thus glides to [j], while /p/ retains [+labial] and glides to [w]. As per Piñeros (2001), /k, g/ overwhelmingly glide to [w], though they occasionally glide to [j]. This alternation is less easily explained, and is outside the scope of this paper. For the purpose of this analysis, $/ \mathrm{k}, \mathrm{g} /$ will be treated as always gliding to $[\mathrm{w}]$.

The pattern in (1) is consistently found with coda stops in Chilean Spanish, demonstrating a clear disfavouring of those segments in that position. Interestingly, sonorants are allowed in the same position, as seen in (2):

(2) Coda Sonorants
a. so.plar $\quad \sim$ [so.plar] (Martínez-Gil 1997)
b. de.si.lu.sjon $\sim$ [de.si.lu.sjon] (Broś 2018)
c. ag.ri.cul.tor ${ }^{1} \sim$ [aw.ri.cul.tor] (Martínez-Gil 1997)

This data shows that sonorant segments are immune to Chilean Spanish's distaste for codas. /n/ remains [n], /l/ remains [1], and $/ \mathrm{r} /$ remains [r]. Something is evidently protecting them from gliding. This

\footnotetext{
${ }^{1}$ As per Broś' (2018) data, complex onsets like /gr/ are permissible in Chilean Spanish. However, they are only allowed when word-initial or if another consonant intervenes between the stop and the preceding vowel. The exact nature of this pattern and its implications for the current analysis are beyond the scope of this paper.
} 
rules out, therefore, any easy analysis in terms of codas' well-attested preference for more sonorous segments (Hooper 1977).

Also important is the lenition of /s/ in Chilean Spanish codas. Coda $/ \mathrm{s} /$ lenites to $/ \mathrm{h} /$ in word-internal codas, and fully deletes when word-final. This is seen in (3) below.

(3) /s/ Lenition (Broś 2018)
a. /esto/ [eh.to]
b. /desde/ [deh.de]
c. $/$ bes $/ \sim[$ be $]$

This data further undermines a simplistic sonority argument, and provides significant trouble for any analysis resting primarily on ${ }^{*} \mathrm{CODA} / \mathrm{Segment}$ constraints. Any explanation of the coda phenomena in Chilean Spanish must account for this coda/s/ lenition.

\section{Gradualness}

In any HS analysis, assumptions about Gradualness are important, often being key to the understanding or function of the argument (McCarthy 2016). Therefore, it is important to be very clear about which assumptions are at work.

First and foremost, this paper assumes that only one feature can be changed, added, or deleted at each step. A feature can be added or removed, or its value changed, but only one at a time. Therefore, if there is an input /p/, then [v] cannot be a possible candidate, because it requires /p/ to change both [voice] and [continuant]. In contrast [b] would be a possible candidate, because it only changes [voice].

This analysis also assumes that all vowels come with an underlying mora, while consonants generally do not (Hayes 1989: 256-257). For the purpose of this analysis, all consonants will be treated as lacking any underlying morae.

Importantly for the analysis of coda /s/ lenition is this paper's adoption of McCarthy's (2008) assumption that deletion is a two-step process. Under this model, it takes one step to delete the [place] node in any given segment, and then another to delete the resulting [h] or [?].

\section{Constraints}

This analysis requires a complex set of constraints to fully analyze the lenition phenomena under consideration. The constraints required for the obstruent analysis are as follows:

(4) WEIGHT-BY-POSITION (WBP): assign a violation mark for every coda which does not bear a mora (Hayes 1989).

(5) *OBSTRUENTMORA: assign a violation mark for every obstruent segment which is associated with a mora.

(6) *SONORANTMORA: assign a violation mark for every [+sonorant] consonant which is associated to a mora.

(7) *?: assign a violation mark for every [?] segment.

The constraint family of *SONORANTMORA can be taken to include *NASALMORA $>>$ *Lateralmora, *RhoticMora $>>$ GlideMora. Similarly, the *ObStruentMora family includes *VOICELESSSTOPMORA $>>*$ VOICEDSTOPMORA $>>*$ VOICELESSFRICATIVEMORA $>>*$ VOICEDFRICATIVE 
MORA. These more specific constraints will be used when appropriate, such as when judging between [p] and $[\mathrm{b}]$. When the specifics of these constraints are not required, such as when comparing [p] to [n], the more generic constraint will be used for brevity. Both *OBSTRUENTMORA and *SONORANTMORA have fixed internal rankings because they represent the sonority scale, which is universal in human language. Codas universally prefer more sonorous segments (Hooper 1977). If phonological patterns are the result of constraints, then a universal pattern must be the result of a universal ranking. Therefore, both of these constraint families are taken to have internally fixed rankings. Furthermore, *OBSTRUENTMORA outranks *SONORANTMORA in all languages, as obstruents are always less sonorous than sonorants.

Also required for the analysis are the common constraints DEP[mora], DEP[nasal], DEP[lateral], DEP[rhotic], and IDENT. These constraints will also be used to explain how sonorant coda segments are able to surface without changing into glides.

The /s/ lenition analysis will require a slightly different set of constraints. Due to diverging after the first step, the following constraints will be required to explain /s/ lenition:

(8) $*$ CODA/s: assign a violation mark for every /s/ which is syllabified into a coda.

(9) *FINAL/h: assign a violation mark for every word-final $/ \mathrm{h} /$.

These constraints will be combined with IDENT and MAX[place] to explain both word-internal $/ \mathrm{s} / \rightarrow[\mathrm{h}]$ and word-final /s/ deletion.

Note that for the purposes of this analysis, glottal segments are assumed to vacuously satisfy the *OBSTRUENTMORA constraint family. This is based on the somewhat unusual characteristics of glottal segments as regards sonority. Given that glottal segments seem to display features of both sonorant and obstruent segments, it seems best to treat glottal segments as a category apart for the purposes of minimum sonority in this analysis (Parker 2002: 66-67, 224-225). It should, however, be noted that there is much disagreement over the exact nature of glottal segments as regards sonority, and much depends on how one defines the [sonorant] feature (Parker 2002: 65-66).

\section{Analysis}

\subsection{Obstruents}

The analysis will begin by considering coda obstruents. As noted in Section 2, Chilean Spanish /t, d/ lenite to [j], and /p, b, k, g/ generally lenite to [w] (Piñeros 2001). This paper proposes that minimum sonority requirements for mora-bearing segments can explain this pattern. While the tableaux below will focus on $/ \mathrm{p} /$, any stop could be used to the same effect. The only distinction among segments would be that voiced stops do not need to undergo the voicing step. Otherwise, the derivations are functionally identical.

The analysis begins in Tableau (10), below:

(10) Step 1: Mora Insertion

\begin{tabular}{|c||l|c|c|}
\hline /ap.to/ & $\begin{array}{l}\text { WEIGHT- } \\
\text { BY- } \\
\text { POSITION }\end{array}$ & *OBSTRUENTMORA & DEP[mora] \\
\hline \hline a. ap.to & & $*$ & \\
$\begin{aligned} \mu \\
\text { b. ap.to }\end{aligned}$ & $* !$ & & $*$ \\
\hline
\end{tabular}


In this simple step, the constraint WEIGHT-BY-POSITION forces /ap.to/ to add a mora to coda $/ \mathrm{p} /$ in the winning candidate (a). Meanwhile, the faithful Candidate (b) obeys both *OBSTRUENTMORA and DEP[mora] by not adding a mora to coda $/ \mathrm{p} /$. However, this fatally violates the high-ranked WEIGHT-BYPOSITION, thus eliminating (b) and leaving (a) to win out.

With the mora added, the next step must contend with the desires of the *OBSTRUENTMORA constraint family. The result is seen in Tableau (11) below:

(11) Step 2: Voicing

\begin{tabular}{|c|c|c|c|c|c|c|c|}
\hline$\left.\right|_{\mu} ^{\text {/ap.to/ }}$ & *? & WBP & $\begin{array}{l}\text { *VOICELESS } \\
\text { STOPMORA }\end{array}$ & $\begin{array}{l}\text { *VOICED } \\
\text { STOPMORA }\end{array}$ & $\begin{array}{l}\text { *VOICELESS } \\
\text { FRICATIVE } \\
\text { MORA }\end{array}$ & $\begin{array}{l}\text { IDENT } \\
\text { [voice] }\end{array}$ & MAX[place] \\
\hline a. ap.to & & & $* !$ & & & & \\
\hline $\begin{array}{c}\rightarrow \text { b. } \\
\mu \\
\text { [voice] }\end{array}$ & & & & $*$ & & $*$ & \\
\hline c. ap.to & *! & & & & & & $*$ \\
\hline $\begin{array}{c}\text { d. af.to } \\
\mu \\
\text { [continuant] }\end{array}$ & & & & & $* !$ & & \\
\hline
\end{tabular}

Candidate (a), the faithful candidate, violates *Mora/p, a sub-constraint of *OBSTRUENTMORA, and is thus eliminated. Candidate (c), which vacuously satisfies the *OBSTRUENTMORA and *SONORANTMORA constraint families, is eliminated by a high-ranking *?, which bans the use of $/ \mathrm{P} /$ throughout Chilean Spanish. A similar constraint, *VOICELESSFRICATIVEMORA, eliminates candidate (d), preventing alternation to fricative at this step. Importantly, the prevention of this derivational path prevents coronal stops from changing into $/ \mathrm{s} /$ and then leniting into $/ \mathrm{h} /$. This leaves candidate $(\mathrm{b})$, which voices the moraic coda, to win at this step despite violating both IDENT[voice] and *VOICEDSTOPMORA.

Sonorant candidates are prohibited in this step due to Gradualness: they would require both [continuant] and [sonorant], which is more changes than one step allows. However, were they allowed, they would be more harmonic than the current candidate set: *NASALMORA, *LATERALMORA, and *RHOTICMORA are all ranked below the *OBSTRUENTMORA constraints.

Having voiced the moraic coda, the derivation enters a third step, as seen in (12). Here the choice is between remaining faithful and becoming [+continuant]. Based on basic sonority preferences, the outcome is clear. Candidate (a), while it remains faithful, violates *VOICEDSTOPMORA. This constraint outranks *VOICEDFRICATIVEMORA, since $/ \mathrm{b} /$ is less sonorous than $/ \mathrm{v} /$. Therefore, candidate (b) wins, since it only violates the lower-ranked *Mora/v and IDENT[continuant]. 
(12) Step 3: Fricative

\begin{tabular}{|r||l|l|l|l|}
\hline $\begin{array}{l}\text { /ab.to/ } \\
\mu\end{array}$ & WBP & $\begin{array}{l}\text { *VOICED } \\
\text { STOPMORA }\end{array}$ & $\begin{array}{l}\text { *VOICED } \\
\text { FRICATIVE MORA }\end{array}$ & $\begin{array}{l}\text { IDENT } \\
\text { [continuant] }\end{array}$ \\
\hline \hline $\begin{array}{c}\text { a. ab.to } \\
\mu \\
\mu\end{array}$ & & $* !$ & & \\
\hline $\begin{array}{c}\mu \text { av.to } \\
\mu \\
\text { continuant] }\end{array}$ & & & & \\
\hline
\end{tabular}

The sonority increase does not stop here. The derivation must continue, as seen in (13) below.

(13) Step 4: Gliding

\begin{tabular}{|c|c|c|c|c|}
\hline$\left.\right|_{\mu} ^{\text {lav.to/ }}$ & $\begin{array}{l}\text { IDENT } \\
\text { [voice] }\end{array}$ & $\begin{array}{l}\text { *VOICED } \\
\text { FRICATIVE } \\
\text { MORA }\end{array}$ & *GLIDEMORA & IDENT [sonorant] \\
\hline $\begin{array}{r}\text { a. av.to } \\
\mu \\
\text { [continuant] } \\
\text { [voice] }\end{array}$ & & $* !$ & & \\
\hline $\begin{array}{r}\rightarrow \text { b. aw.to } \\
\mu \\
\text { [continuant] } \\
\text { [voice] } \\
\text { [sonorant] }\end{array}$ & & & * & * \\
\hline $\begin{array}{c}\text { e. ah.to } \\
\mu \\
\text { [-voice] }\end{array}$ & $* !$ & & & \\
\hline
\end{tabular}

Several conceivable candidates are omitted here: [ar.to], [al.to], and [an.to]. As discussed in Section 3 , one feature can be added or changed at each step. Each of the possibilities just mentioned, $/ \mathrm{r} 1 \mathrm{n} /$, would add both the feature [+sonorant] and a unique privative feature. /r/ would add [rhotic], /1/ would add [lateral], and $/ \mathrm{n} /$ would add [nasal]. Thus, these are not considered as candidates at this step.

For the candidates eligible for this step, there is a clear winner. Candidate (a), while faithful, still violates *VOICEDFRICATIVEMORA, which outranks *GLIDEMORA. Thus, the more sonorous candidate (b) wins out, despite also violating IDENT[sonorant]. This shows again a clear movement towards greater sonority for the moraic segment. Meanwhile, the potential for place-deletion at this step is prevented by IDENT[voice]. This demonstrates the importance of the lenition order: if the underlying stops do not voice first, then they can become voiceless fricatives, and there is no reason why they should not reduce to $[\mathrm{h}]$. By using IDENT[voice], this potential is prevented: the stops all voice due to the requirements of constraints ranked above IDENT[voice], and henceforth treat [+voice] as part of the input, thereby preventing future devoicing.

The final step comes in (14), which demonstrates how the analysis prevents full vocalization. 
(14) Step 5: Convergence

\begin{tabular}{|c|c|c|c|c|c|c|}
\hline$\left.\right|_{\mu} ^{\text {/aw.to/ }}$ & $\begin{array}{l}\text { DEP } \\
\text { [nasal] }\end{array}$ & $\begin{array}{l}\text { DEP[lateral] } \\
\text { nal }\end{array}$ & DEP[rhotic] & $\begin{array}{l}\text { DEP[syllabic } \\
\text { head] }\end{array}$ & *GLIDEMORA & $\begin{array}{l}* \text { HIGH } \\
\text { VOWEL } \\
\text { MORA }\end{array}$ \\
\hline$\rightarrow$ a. aw.to & & & & & * & \\
\hline $\begin{array}{l}\text { b. a.u.to } \\
\text { [syllabic } \\
\text { head] }\end{array}$ & & & & $* !$ & & $*$ \\
\hline c. ar.to & & & $* !$ & & & \\
\hline d. al.to & & $* !$ & & & & \\
\hline e. $\left.\right|_{\mu} ^{\text {an.to }}$ & $* !$ & & & & & \\
\hline
\end{tabular}

At this stage the more complex sonorant candidates are evaluated. Each of them is in turn prevented by a DEP constraint. Candidate (c) violates DEP[rhotic], (d) by DEP[lateral], and (e) by DEP[nasal]. Thus, Chilean Spanish displays no desire to add more complexity to the segment than is necessary. This leaves candidate (b) to challenge the input of this step. By fully syllabifying, (b) satisfies all constraints banning moraic consonants. However, DEP [syllabic head] is violated by (b), and thus it is ruled out in favour of the faithful (a). Since the winning candidate is identical to the input at this step, the derivation reaches convergence here.

This derivation explains why so non-sonorous a segment as $/ \mathrm{p} /$ must transform into a glide, rather than simply voicing, nasalizing, or becoming a rhotic or lateral segment. From this data no clear ordering of the DEP constraints can be determined, due to no winning candidate favouring any of them. However, an exact ranking is not needed for this data: all that matters is that they are ranked highly enough to override *GlideMora and the *OBSTRUENTMORA sub-family. That is, Chilean Spanish finds it worse to add a [nasal], [lateral], or [rhotic] node than to have a mora on an obstruent or on [w].

\subsection{Nasal, Laterals, and Rhotics}

In contrast to stops, Chilean Spanish Nasals, Laterals, and Rhotics surface in the coda unchanged. This outcome is predicted by this paper's analysis. Observe the derivation in tableau (15), below. Note that this derivation omits the constraints DEP[lateral], DEP[rhotic], MAX[rhotic], and MAX[lateral] and DEP[syllabic head]. This is due to the non-influence they have on the outcome of this specific derivation. If a rhotic or lateral were to be analyzed, the relevant constraint would be used in place of the [nasal] constraints.

${ }^{2}$ This paper is not necessarily claiming that [syllabic head] is truly a feature. This is used for the mechanical purpose of demonstrating a preference against making a segment into a syllabic head. This could easily be some sort of Hiatus constraint. 
(15) Step 1: Adding the Mora

\begin{tabular}{|c||c|c|c|}
\hline $\begin{array}{c}\text { /ten.so/ } \\
\mu\end{array}$ & WBP & DEP[mora $]$ & *SONORANTMORA \\
\hline $\begin{array}{c}\text { a. ten.so } \\
\text { b. ten.so } \\
\mu\end{array}$ & $* !$ & & \\
\hline & & $*$ & \\
\hline
\end{tabular}

Tableau (15) shows the addition of a mora to coda /n/, with Weight-by-Position banning the nonmoraic candidate (a). Thus, despite violating DEP[mora] and *SonorantMora, candidate (b) wins out.

This leads into the second step, in (16), where this derivation diverges from that of Chilean Spanish stops.

(16) Step 2: Convergence

\begin{tabular}{|c|c|c|c|c|}
\hline$\left.\right|_{\mu}$ & *? & MAX[nasal] & *NASALMORA & *GLIDEMORA \\
\hline $\begin{array}{c} \\
\mu \\
\mu\end{array}$ & & & \% & \\
\hline $\begin{array}{cc}\text { b. tej.so } \\
\mu \\
\mu\end{array}$ & & $* !$ & & $*$ \\
\hline a. te?.so & $* !$ & & & \\
\hline
\end{tabular}

This tableau shows that a moraic nasal coda segment should surface. Candidate (b), which increases the coda's sonority, nonetheless violates a high-ranked MAX[nasal] constraint, and is thus eliminated. Similarly, candidate (c), which tries to vacuously satisfy the *SEGMENTMORA constraints by reducing to [h], fatally violates MAX[place]. This leaves candidate (a), the faithful candidate at this step, to win. The derivation thus reaches convergence.

A similar process takes place for lateral and rhotic codas. The only difference is that instead of MAX[nasal], they are protected by MAX[lateral] and MAX[rhotic] respectively. Thus, the analysis neatly explains why low-sonority segments, such as $/ \mathrm{p} /$ and $/ \mathrm{b} /$, will lenite all the way to glides, but these underlyingly more sonorous segments remain faithful. It is a matter of avoiding violations of *OBSTRUENTMORA, and obeying protections on more complex prosodic structure.

\subsection{Fricative $/ \mathrm{s} /$}

While stops and sonorants can be easily explained by the current analysis, coda $/ \mathrm{s} /$ is somewhat more complex. Unlike the stops, Chilean Spanish coda /s/ lenites not to a glide, but to [h]. Furthermore, if /s/ is the final segment of the word, it entirely deletes. This demonstrates a different path than the one followed by stops, though one which can be handled by the current analysis, with some modification.

The derivation begins just the same as with stops and with sonorants, by adding the mora as in (17). 
(17) Step 1: Adding the Mora

\begin{tabular}{|r||c|c|c|}
\hline$/$ es.to/ & WBP & *OBSTRUENTMORA & DEP[mora] \\
\hline \hline $\begin{array}{r}\rightarrow \text { a. es.to } \\
\mu\end{array}$ & & $*$ & $*$ \\
\hline b. es.to & $* !$ & & \\
\hline
\end{tabular}

As before, WEIGHT-BY-POSITION neatly enforces the addition of a mora to coda $/ \mathrm{s} /$, ruling out the non-moraic candidate (b). This favours candidate (a), which has added a mora. The divergence begins at the next step.

(18) Step 2: Lenition

\begin{tabular}{|c|c|c|c|c|}
\hline $\begin{array}{c}\text { /es.to/ } \\
\mid \\
\mu \\
\end{array}$ & WBP & $\begin{array}{l}\text { *VOICELESS } \\
\text { FRICATIVE MORA }\end{array}$ & $\begin{array}{l}\text { *VOICED } \\
\text { FRICATIVE } \\
\text { MORA } \\
\end{array}$ & MAX[place] \\
\hline $\begin{array}{cc}\text { a. es.to } \\
\mid \\
\mu\end{array}$ & & $* !$ & & \\
\hline \begin{tabular}{cc} 
\\
\multicolumn{1}{c}{ b. ez.to } \\
$\mu$
\end{tabular} & & & $* !$ & \\
\hline $\begin{array}{c}\rightarrow \text { c. eh.to } \\
\mid\end{array}$ & & & & $*$ \\
\hline
\end{tabular}

Here, instead of voicing like the stops did, coda /s/ lenites to [h]. This results from the ranking of MAX[place]. The faithful candidate (a) violates *VOICELESSFRICATIVEMORA, which would favour candidate (b), which only violates the lower-ranked *VOICEDFRICATIVEMORA. However, candidate (c) vacuously satisfies the entirety of the *OBSTRUENTMORA family by deleting place. This violates MAX[place], but that constraint is ranked low enough so as to not affect the outcome. Therefore, candidate (c) wins.

At the next step, the derivation converges with the output/eh.to/. The only significant differences are the lack of MAX[place] violations, and the presence of some DEP constraint which prevents full deletion.

The divergence of /s/-lenition from stop lenition deserves some further discussion. It is strange to see, considering that stops voice rather than delete to $/ \mathrm{R} /$. The key difference is proposed to be the phonemic inventory of Chilean Spanish: it lacks / // (Lipski 1994; Martínez-Celdrán et al. 2003). Thus the constraint *? is used to represent the inability of Chilean Spanish to resort to this segment as a solution. However, for fricatives, Chilean Spanish does have the glottal continuant, $/ \mathrm{h} /$. Therefore, there is no high-ranked $* h$ preventing place-deletion as a solution to moraic sonority.

The current analysis is able to not only explain the above /s/-lenition, but also the full deletion /s/ experiences word-finally. Consider (19-21) below: 
(19) Step 1: Add Mora

\begin{tabular}{|r||l|c|c|}
\hline /bes/ & WBP & *OBSTRUENTMORA & DEP[mora] \\
\hline \hline $\begin{array}{c}\text { a. bes } \\
! \\
\mu\end{array}$ & & $*$ & $*$ \\
\hline b. bes & $* !$ & & \\
\hline
\end{tabular}

This derivation begins the same way as all the others, neatly adding the mora to obey WEIGHT-BYPOSITION.

(20) Step 2: Lenition

\begin{tabular}{|r||l|c|l|l|}
\hline $\begin{array}{l}\text { /bes/ } \\
\mu\end{array}$ & WBP & $\begin{array}{l}\text { *VICELESS } \\
\text { FRICATIVE MORA }\end{array}$ & $\begin{array}{l}\text { *VOICED } \\
\text { FRICATIVE } \\
\text { MORA }\end{array}$ & MAX[place] \\
\hline \hline a. bes & & $* !$ & & \\
$\mu$ & & & & \\
\hline b. bez & & & & \\
$\mu$ & & & & \\
\hline c. beh & & & & \\
\hline & & & & \\
\hline
\end{tabular}

Again, this derivation so far follows the pattern set by word-internal coda $/ \mathrm{s} /$, deleting place to vacuously satisfy the *OBSTRUENTMORA constraint family.

(21) Step 3: Full Deletion

\begin{tabular}{|c|c|c|}
\hline $\begin{array}{c}\text { /beh/ } \\
\mu\end{array}$ & *FINAL/h & MAX [segment] \\
\hline $\begin{array}{r}\rightarrow \text { a. be } \\
\mid \\
\mu\end{array}$ & & * \\
\hline b. beh & $* !$ & \\
\hline
\end{tabular}

It is at step 3 that this pattern diverges. Instead of simply leniting to $/ \mathrm{h} /$ like word-internal coda $/ \mathrm{s} /$, word-final /s/ fully deletes. This part of the derivation results from a process separate from moraic sonority, however. Rather, this paper proposes that unrelated prosodic concerns in Chilean Spanish disfavour final $/ \mathrm{h} /$, and thus will delete the segment if it appears in that context. Thus, the two constraints used in Step 3 are unseen elsewhere. Candidate (b) violates the constraint *FINAL/h, which outranks MAX[segment] to favour candidate (a). This leads to full deletion, and the attested output [be].

The only remaining question here is what exactly happens to the leftover mora. Martínez-Celdrán et al. (2003) and Lipski (1994) indicate that Chilean Spanish does not appear to have vowel length contrasts. Thus, whatever the result, it cannot be a phonemic vocalic length change. However, this paper has treated 
the derivation as having transferred the mora over to the vowel to cause an allophonic, that is, sub-phonemic change. Still, further research is required to resolve this mystery.

\subsection{Final Constraint Ranking}

The final constraint ranking for Chilean Spanish coda obstruent lenition is, therefore as follows:

\section{(22) Constraint Ranking}

Weight-By-Position, *?, *FinAL/h, Dep[nasal], DeP[rhotic], DeP[lateral], MAX[nasal], MAx[lateral], MAX[rhotic] > DEP[mora], *OBSTRUENTMORA $>$ IDENT[syllabic head] $>>$ *SONORANTMORA $>>$ IDENT[sonorant], IDENT[continuant], IDENT[voice] MAX[place]

This demonstrates a clear disfavouring of moraic obstruents, and an even greater disfavouring of unnecessary prosodic complication. Chilean Spanish does not want to add more prosodic structure, and does so only when other options are exhausted. The ranking also shows a preference for deletion, with other forms of lenition only being used to work around phonemic gaps.

\section{Future Predictions}

This analysis makes several typological predictions. First and foremost, it predicts that languages will prefer to delete place rather than alter the coda segment. The coda sonority constraints can be easily vacuously satisfied with a glottal segment, and the current analysis shows that alternatives only occur when someone blocks place-deletion. In Chilean Spanish the trouble comes from a lack of / / in the phonological inventory. It is conceivable that languages which allow / / could also block place-deletion simply by having MAX[place] ranked above the *SEGMENTMORA family.

For those languages which are, for some reason, forced to lenite their coda segments, this analysis predicts that gliding will be more common than nasalization, rhotacization, or lateralization. Despite nasals, laterals, and rhotics being less sonorous than glides, and therefore closer in sonority to obstruents, this analysis treats them as being more complex than glides. In this analysis, glides can be defined as [sonorant, voice, continuant], while laterals will be [sonorant, voice, continuant, lateral], nasals will be [sonorant, voice, continuant, nasal], and rhotics will be [sonorant, voice, continuant, rhotic]. Due to having this extra node, nasals, rhotics, and laterals are predicted to be built from glides in terms of features. Therefore, it would be harder to transform an obstruent into a nasal, lateral, or rhotic than into a glide. Relatedly, this analysis predicts that nasals, rhotics, and laterals will be typologically less common than glides, as they are more complex.

The analysis touches on problems regarding the analysis of $[\mathrm{h}]$ and other glottal segments. Here, $[\mathrm{h}]$ is said to vacuously satisfy *VOICELESSFRICATIVEMORA. However, on a technical level, $[\mathrm{h}]$ is a voiceless fricative. This is a major problem for the current proposal. However, there is some evidence to suggest that glottal segments pattern more like sonorants than obstruents (Parker 2002: 65-66). Still, there remains much controversy over the classification of [h] (Ibid). Further research is required to properly understand the interaction of $[\mathrm{h}]$ with *VOICELESSFRICATIVEMORA, but for the moment it seems plausible to treat $[\mathrm{h}]$ as acting like a sonorant and thus would be unaffected by *VOICELESSFRICATIVEMORA.

This analysis predicts a relatively strict order of lenition in codas. If / $/$ / were allowed to add [continuant] before it became voiced, then it would lenite to [s]. This, in an HS system, would allow the resulting [s] to place-delete into [h], thus producing an unattested form. Even if the voiceless stops voice before they gain [continuant], there is possibly a problem as to why the eventual voiced fricatives cannot pace-delete into [h]. This account has no explanation for this at the current time, and further research is required to understand what seems to be protecting voiced fricatives from place-deletion in this system.

Currently, it is predicted that final [h] deletion will result in a leftover mora, and it is assumed that this mora simply attaches to the preceding vowel. However, further research on the phonetics of Chilean 
Spanish is required to determine if this is the actual result. An alternative, it is reasonable to assume that after $[\mathrm{h}]$ deletion, the extra mora is itself deleted by some constraint banning unassociated morae.

\section{Conclusion}

This paper has argued for a unified analysis of Chilean Spanish coda obstruent lenition motivated by moraic sonority concerns. It has brought both $/ \mathrm{s} / \rightarrow[\mathrm{h}]$ lenition and obstruent gliding under a single analysis, with the two lenition paths diverging based on the licensing of glottal segments. The paper has argued for a fixed ranking of coda sonority constraints universally. From this, the paper has argued that coda lenition in Chilean Spanish is driven by minimum sonority requirements on coda consonants, with the fixed *SEGMENTMORA family forcing lenition on fricatives and stops. Fricatives have been shown to delete their place nodes and reduce to $[\mathrm{h}]$ in order to vacuously satisfy minimum sonority requirements. In contrast, due to the absence of [?] from Chilean Spanish, stops cannot licitly place-delete. Therefore, they have to lenite into glides, due to no stops or fricatives being sufficiently sonorous to bear morae. Gliding occurs due to glides being featurally simpler than nasals, laterals, or rhotics, and being sufficiently sonorous to bear morae in Chilean Spanish. This proposal also explains why nasals, rhotics, and laterals do not lenite into glides, as they are already sufficiently sonorous for moraicity, and thus do not trigger the lenition.

\section{References}

Broś, Karolina. 2018. Contiguity in prosodic words: Evidence from Spanish. Poznan Studies in Contemporary Linguistics 54(1): 37-82.

Hayes, Bruce. (1989). Compensatory lengthening in Moraic Phonology. Linguistic Inquiry 20(2): 253-306. Hooper, Joan B. 1977. An introduction to natural generative phonology. New York: Academic Press.

Lipski, John M. 1994. Latin American Spanish. New York: Longman.

Martínez-Celdrán, Eugenio, Ana Ma. Fernández-Planas, and Josefina Carrera-Sabaté. 2003. Castilian Spanish. Journal of the International Phonetic Association 33(2): 255-259.

Martinéz-Gil, Fernando. 1997. Obstruent vocalization in chilean spanish: A serial versus a constraint-based approach. Probus 9(2): 167-202.

McCarthy, John J. 2008. The gradual path to cluster simplification. Phonology 25(2): 271-319.

McCarthy, John J. 2016. The theory and practice of Harmonic Serialism. In Harmonic Grammar and Harmonic Serialism, ed. John J. McCarthy and Joe Pater, 47-87. London: Equinox.

McCarthy, John J. 2018. How to delete. In Perspectives on Arabic Linguistics XXX, ed. Amel Khalfaoui and Matthew A. Tucker, 7-32. Amsterdam: John Benjamins.

Parker, Stephen G. 2002. Quantifying the sonority hierarchy. Doctoral dissertation, University of Massechusetts. Retrieved from Dallas International University Library. Accession no. AAI3056268

Piñeros, Carlos-Eduardo. 2001. Segment-to-syllable alignment and vocalization in Chilean Spanish. Lingua 111(3): 163-188. doi:10.1016/s0024-3841(00)00029-2 